\title{
S? Journals BAHIANA \\ Planejamento estratégico na promoção à saúde do idoso: uma experiência integradora academia-serviço-comunidade
}

\author{
Strategic planning in the health promotion of the elderly: an \\ academy-service-community integration experience
}

\section{Carla Maria Lima Santos ${ }^{1}$, Suélem Maria Santana Pinheiro Ferreira ${ }^{2}$, Carla Santos Almeida ${ }^{3}$, Igor Brasil de Araújo4, Ana Caroline de Marino5, Valnice Machado Menezes ${ }^{6}$}

'Autora para correspondência. Universidade do Estado da Bahia, Salvador, Bahia, Brasil. ORCID: 0000-0001-8620-2313. carlamarialima_4@hotmail.com Universidade do Estado da Bahia, Salvador, Bahia, Brasil. ORCID: 0000-0002-4470-3168. suelem.pinheiro@gmail.com 3Universidade do Estado da Bahia, Salvador, Bahia, Brasil. ORCID: 0000-0002-4594-7375. carla_reb@hotmail.com

${ }^{4}$ Universidade do Estado da Bahia, Salvador, Bahia, Brasil. ORCID: 0000-0002-7429-2136. brasilsoueu@gmail.com ${ }_{5}^{5}$ Secretaria Municipal de Saúde de Salvador, Salvador, Bahia, Brasil. ORCID: 0000-0002-5257-7595. anacarolinemarino@yahoo.com.br ${ }^{6}$ Secretaria Municipal de Saúde de Salvador, Salvador, Bahia, Brasil. ORCID: 0000-0001-8472-285X.nicemenezes76@hotmail.com

RESUMO | INTRODUÇÃO: O planejamento em saúde pode ser compreendido como um dispositivo para sistematização das ações e facilitação na elaboração dos processos de trabaIho, bem como para a formação de profissionais de saúde engajados à organização do Sistema Único de Saúde. OBJETIVO: Discutir o envolvimento de diversos atores sociais na construção coletiva do Planejamento Estratégico Situacional em um componente curricular da formação em saúde e levantar potenciais benefícios desse processo. MATERIAIS E MÉTODOS: Os discentes tiveram aporte teórico sobre Sistema Único de Saúde, Promoção da Saúde, Epidemiologia, Planejamento, Educação Popular durante os três semestres do componente curricular supracitado. No segundo semestre foi realizado diagnóstico situacional da população de um grupo de idosos da USF. Com base nesse diagnóstico, no terceiro semestre, juntamente à equipe da USF, docentes e os idosos, foi realizado Planejamento Estratégico Situacional (PES), conforme teoria de Carlos Matus, de intervenções comunitárias com base na Educação Popular em Saúde. RESULTADOS: O PES, com a participação de todos os atores, possibilitou a horizontalidade das relações em todas as etapas, desde o planejamento até a execução das atividades. Foram realizadas 5 intervenções comunitárias com os idosos, com posterior avaliação e monitoramento das ações. CONCLUSÃO: Os resultados apontam para o papel potencializador dessa prática integradora e a importância da vivência no SUS desde o início do percurso acadêmico.

PALAVRAS-CHAVE: Educação em saúde. Planejamento em saúde. Saúde do idoso. Serviços de saúde.
ABSTRACT | INTRODUCTION: Health planning can be understood as a device for systematizing actions and facilitating the elaboration of work processes, as well as for the training of health professionals engaged in the organization of the Unified Health System. OBJECTIVE: To discuss the involvement of several social actors in the collective construction of Situational Strategic Planning in a curricular component of health graduation courses and to highlight potential benefits of this process. MATERIALS AND METHODS: The students had theoretical basis about the Unified Health System, Health Promotion, Epidemiology, Health Planning and Popular Education during the three semesters of the above mentioned curricular component. In the second semester, a situational diagnosis was made of a group of elderly people of USF. Based on this diagnosis, in the third semester, along with the USF team, teachers and the elderly from the group, Situational Strategic Planning (PES), according to Carlos Matus, of community interventions based on Popular Health Education was carried out. RESULTS: The PES, with the participation of all the actors, made possible the horizontality of the relations during the process, from the planning to the execution of the activities. Five community interventions were carried out with the elderly, with subsequent evaluation and monitoring. CONCLUSION: The results point to the potential role of this integrative practice and the importance of experiencing SUS since the beginning of the academic course.

KEYWORDS: Health education. Health planning. Health of the elderly. Health services. 


\section{Introdução}

O planejamento em saúde pode ser compreendido como um dispositivo para sistematização das ações e racionalização dos processos de trabalho, visto que estes, a depender da realidade, são complexos e demandam organização prévia'. Portanto, atuar em um território requisita, dos trabalhadores de saúde, habilidades e competências para o reconhecimento das dinâmicas sociais e capacidade de articulação entre os diferentes sujeitos envolvidos no arranjo do espaço.

Com o avanço do Sistema Único de Saúde (SUS), a reorganização dos serviços de saúde no Brasil e a emergência da Estratégia de Saúde da Família como porta de entrada preferencial dos usuários no SUS, as práticas de saúde assumiram um caráter transformador e passaram a fomentar discussões no âmbito acadêmico acerca da formação profissional em saúde. A concepção do perfil de um trabalhador de saúde distante da perspectiva biológico-centrada e curativista, mas voltado às ações para promoção da saúde, cuidado integral e qualidade de vida tornouse, e ainda é, um desafio aos centros formadores².

Os currículos engendrados e desarticulados, dissociando teoria e prática, são um dos muitos desafios para que os estudantes possam compreender a saúde de forma ampliada com incorporação dos determinantes sociais do processo saúde-doença. As alterações curriculares visam atender à complexidade de processos de trabalho promotores de saúde e dissociados da doença como objeto central das ações. Nessa perspectiva, deve-se considerar a atenção básica (AB) o local de preferência para a inserção do discente em saúde e reconhecimento da estruturação do trabalho ${ }^{2,3}$.

Junges, Barbiani e Zoboli1 trazem o processo de trabalho na atenção básica peças-chave fundamentais, como a organização em equipe e a corresponsabilização'. Moreira e Dias, ao discutirem as Diretrizes Curriculares Nacionais (DCN), acrescentam que a formação profissional deve incluir o planejamento crítico-reflexivo juntamente à equipe do serviço da organização da atenção à saúde da população do território, bem como o desenvolvimento de competências comunicacionais em saúde e estratégias para lidar com situações imprevistas4.
As DCN, fruto da articulação intersetorial entre Ministério da Educação (MEC) e Ministério da Saúde (MS), possibilitaram maior autonomia para a estruturação dos componentes curriculares pelas universidades, norteando que os cursos de graduação em saúde ressaltem a integralidade do cuidado, a atuação em equipe multiprofissional, o conhecimento dos determinantes do processo saúde-doença e vivências práticas (integração ensino-serviço) ${ }^{4}$.

Não obstante a importância inequívoca da atenção à saúde nos diferentes níveis de complexidade e a presença de profissionais que atendam as demandas inerentes a cada nível, nosso objetivo é problematizar a recorrência de graduações de saúde com priorização da abordagem terapêutica curativista, das "superespecialidades" e da alta densidade tecnológica e reduzido enfoque na educação em saúde, cuidado e nos determinantes sociais no planejamento em saúde ${ }^{2,5}$.

Diante da potencialidade que a integração ensino e serviços de saúde confere à formação profissional, este estudo tem como objetivo discutir o envolvimento de diversos atores sociais na construção coletiva do Planejamento Estratégico Situacional de um componente curricular da formação em saúde e levantar potenciais benefícios desse processo. Para isso, foi utilizada a experiência do Projeto Saber Envelhecer, que contemplou discentes e docentes de seis cursos de graduação em saúde, trabalhadores de uma USF e usuários idosos adscritos.

\section{Proposta articuladora de formação acadêmica: do (re)conhecimento do território à análise de situação de saúde}

O componente curricular Programa de Integração Academia, Serviço e Comunidade - PIASC propõe uma abordagem teórico-prática multiprofissional/ interdisciplinar do cuidado e práticas vivenciais durante todo o seu transcurso, ambientadas na atenção básica, com solidificada integração ensino-serviço-comunidade. PIASC perpassa os três primeiros semestres da graduação dos seis cursos de graduação em saúde: Enfermagem, Farmácia, Fisioterapia, Fonoaudiologia, Medicina e Nutrição (Quadro 1). 


\begin{tabular}{|c|c|c|c|}
\hline & $\begin{array}{c}\text { Primeiro semestre } \\
\text { PIASC I }\end{array}$ & $\begin{array}{c}\text { Segundo semestre } \\
\text { PIASC II }\end{array}$ & $\begin{array}{c}\text { Terceiro semestre } \\
\text { PIASC III }\end{array}$ \\
\hline Eixos temáticos & $\begin{array}{l}\text { 1. Processo saúde-doença } \\
\text { 2. Determinantes sociais da saúde e } \\
\text { promoção da saúde } \\
\text { 3. Modelos de atenção à saúde } \\
\text { 4. Reforma sanitária e Sistema Único de } \\
\text { Saúde } \\
\text { 5. Atenção Primária à Saúde - APS, } \\
\text { território e produção de saúde }\end{array}$ & $\begin{array}{l}\text { 1. Condições de vida e saúde da } \\
\text { população brasileira } \\
\text { 2. Vigilância da saúde } \\
\text { 3. Planejamento em saúde - análise } \\
\text { situacional/ diagnóstico situacional }\end{array}$ & $\begin{array}{l}\text { 1. Intervenção na comunidade } \\
\text { 2. Planejamento em saúde - } \\
\text { planejamento e programação } \\
\text { local em saúde } \\
\text { 3. Educação e comunicação em } \\
\text { saúde }\end{array}$ \\
\hline Estratégias & $\begin{array}{l}\text { Discussões dialogadas; seminários; } \\
\text { estudo de casos; visitas técnicas às } \\
\text { unidades de saúde; visitas domiciliares, } \\
\text { territorialização; diários de campo }\end{array}$ & $\begin{array}{l}\text { Estudos de caso; pesquisa virtual } \\
\text { orientada aos sistemas de vigilância à } \\
\text { saúde; discussões dialogadas; } \\
\text { seminários; elaboração e aplicação de } \\
\text { instrumento de coleta; análise dos } \\
\text { dados coletados; construção de } \\
\text { relatório com análise situacional; } \\
\text { devolutiva do diagnóstico à } \\
\text { comunidade }\end{array}$ & $\begin{array}{l}\text { Oficinas de leitura; rodas de } \\
\text { conversa; seminários, oficinas } \\
\text { para elaboração de PES e PPLS } \\
\text { com os atores da comunidade; } \\
\text { intervenções comunitárias }\end{array}$ \\
\hline Competências & $\begin{array}{l}\text { - Compreensão sócio-histórica da Reforma } \\
\text { Sanitária Brasileira e criação do Sistema } \\
\text { Único de Saúde; } \\
\text { - Conhecimento dos modelos de atenção } \\
\text { à saúde e os paradigmas que os } \\
\text { norteiam; } \\
\text { - Reconhecimento dos aspectos } \\
\text { conceituais e aplicabilidade dos } \\
\text { determinantes sociais de saúde; } \\
\text { - Entendimento da reorganização dos } \\
\text { sistemas de saúde mediante a APS, a } \\
\text { Promoção da Saúde e disposição } \\
\text { territorial; } \\
\text {-Aptidão ao trabalho interdisciplinar e } \\
\text { humanizado }\end{array}$ & $\begin{array}{l}\text { - Compreensão do processo de } \\
\text { transição demográfica, epidemiológica, } \\
\text { nutricional, tecnológica e seus impactos } \\
\text { no sistema de saúde; } \\
\text { - Habilidade para manuseio e } \\
\text { interpretação dos dados dos Sistemas } \\
\text { de Informação em Saúde; } \\
\text { - Identificação das necessidades de } \\
\text { saúde; } \\
\text { - Capacitação para realização de } \\
\text { diagnóstico situacional; } \\
\text { - Aptidão para sensibilizar os atores } \\
\text { sociais sobre a importância do DS como } \\
\text { uma etapa do planejamento em saúde } \\
\text { e o trabalho interdisciplinar }\end{array}$ & $\begin{array}{l}\text { - Assimilação dos aspectos } \\
\text { teóricos do planejamento em } \\
\text { saúde, educação popular em } \\
\text { saúde e intervenção comunitária; } \\
\text { - Conhecimento das principais } \\
\text { correntes teóricas do } \\
\text { planejamento em saúde; } \\
\text { - Capacitação para execução de } \\
\text { planejamento em saúde; } \\
\text { - Habilitação para realização de } \\
\text { intervenções e ações em saúde; } \\
\text { - Aptidão para o trabalho } \\
\text { interdisciplinar e intersetorial }\end{array}$ \\
\hline
\end{tabular}

Fonte: Elaboração própria baseada nas ementas dos componentes curriculares.

O vínculo com a Secretaria Municipal de Saúde de Salvador possibilitou o convênio entre a universidade e os distritos sanitários, de forma que as vivências práticas do PIASC ocorrem nas unidades básicas de saúde e seus territórios de abrangência. Visando a formação interdisciplinar, vinte turmas teórico-práticas são formadas por semestre com preferencialmente três estudantes de cada um dos cursos de graduação. Os discentes são matriculados por comunidades, de forma aleatória, buscando-se a permanência do estudante no mesmo local durante os três semestres, com o mesmo docente. Essa estratégia possibilita construção de vínculo, corresponsabilização e longitudinalidade do cuidado (Figura 1). 
Figura 1. Exemplo de organização prevista de cada componente disciplinar do Programa de Integração Academia, Serviço e Comunidade, de acordo com a comunidade e o curso de graduação do estudante

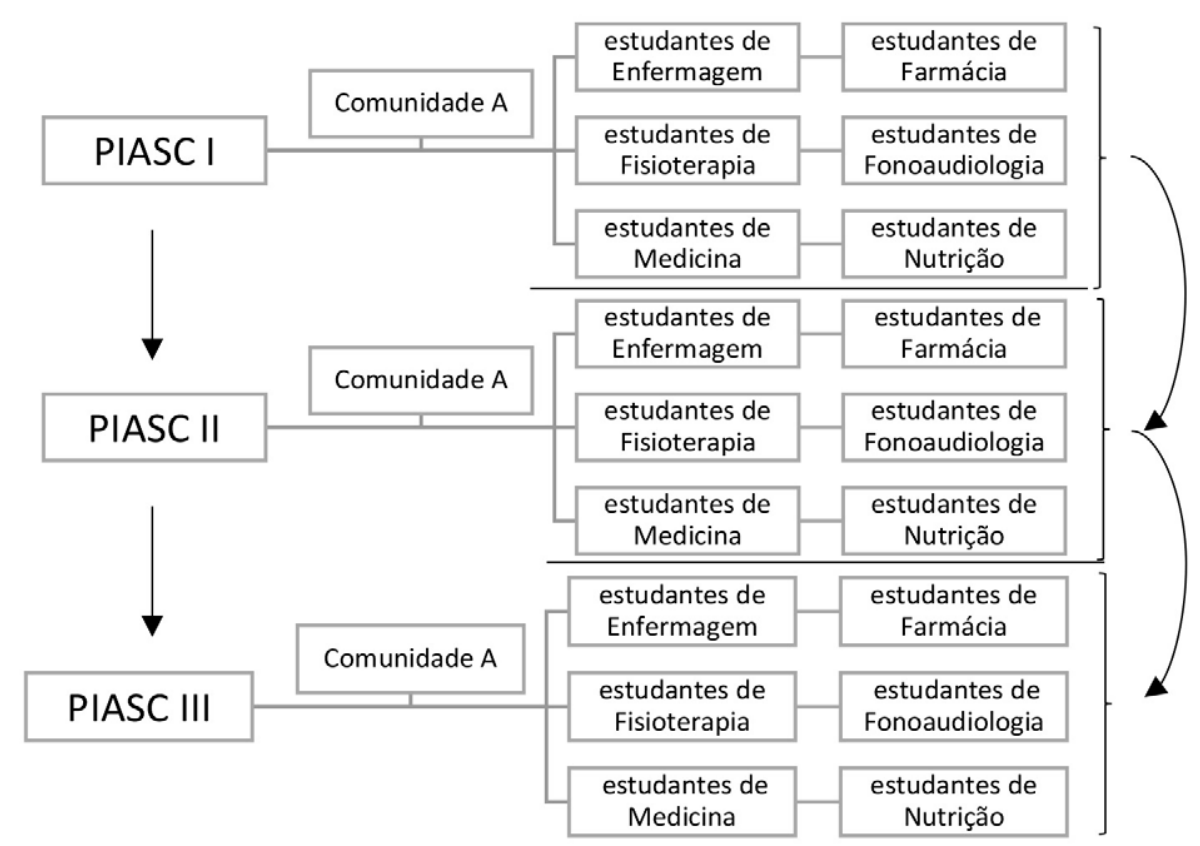

Fonte: Elaboração própria de acordo com o regimento do Programa de Integração Academia, Serviço e Comunidade, Universidade do Estado da Bahia.

As estratégias teóricas e práticas adotadas propõem a integração ensino-serviço-comunidade com o intuito de proporcionar uma formação profissional inserida no paradigma biopsicossocial de atenção à saúde. No primeiro semestre, o aporte teórico discute saúde-doença e seus determinantes, promoção da saúde, modelos de atenção à saúde, Reforma Sanitária Brasileira e contexto histórico de formulação das políticas de saúde e do SUS e o corpo de conhecimentos e práticas da Estratégia de Saúde da Família. Nas atividades de campo são realizadas visitas técnicas às unidades básicas para entendimento de sua lógica organizacional, práticas de territorialização, visitas domiciliares e reconhecimento de território de adscrição das ESF, sua dinamicidade e os fatores que se constituem como determinantes do processo saúde-doença ${ }^{5,6}$.

Articuladas a essa primeira vivência, no segundo semestre (PIASC II), as discussões aprofundam com as condições de vida e saúde da população brasileira (nacional, regional e local), a importância da vigilância em saúde na compreensão das necessidades da população, e a incorporação dos indicadores de morbimortalidade na organização dos processos de trabalho. Nesse ínterim, as discussões subsidiam a adoção de práticas de saúde singulares, direcionadas ao equacionamento das diferenças de saúde entre classes sociais e frações de classe ${ }^{6}$. De modo a introduzir o Planejamento Estratégico em Saúde para intervenção comunitária, a execução da análise situacional é uma das etapas essenciais do PES e é um dispositivo fundamental para a identificação de problemas e necessidades de um grupo populacional. O diagnóstico situacional conta com o envolvimento de todos os atores (serviço, comunidade, gestão e ensino), desde a definição da situação-problema até à análise dos dados, passando pela construção e aplicação do instrumento de coleta ${ }^{7}$ (Quadro 1).

Outra estratégia que compõe o PIASC II é o manuseio orientado dos Sistemas de Informação em Saúde como o DATASUS, Vigilância Epidemiológica e a Sala de Apoio à Gestão Estratégica (SAGE) para desenvolvimento da percepção crítica de como se modelam as necessidades de acordo com as características da população. Além dos dados estruturados, os não estruturados também têm sua importância destacada durante todo o percurso teórico e prático da análise situacional. Quando a estratégia de diagnóstico segue uma abordagem qualitativa são disponibilizados os subsídios essenciais para execução de todo o processo. No PIASC III são trabalhados o suporte teórico do Planejamento Estratégico em Saúde com explanação das principais correntes, além da elaboração interdisciplinar e intersetorial da intervenção comunitária a partir do momento explicativo realizado em PIASC II. A condução das ações, encadeadas 
desde o primeiro semestre, são descritas a seguir para melhor entendimento do processo.

\section{Planejamento Estratégico em Saúde: da análise situacional à intervenção comunitária}

Teixeira, Vilasbôas e Jesus ${ }^{8}$ trazem a análise situacional em saúde como o diagnóstico dos problemas de saúde de um determinado grupo ou população, com vistas à intervenção sobre as necessidades para meIhoria de indicadores das condições de saúde através de intervenções. Portanto para se realizar o PES é necessário o envolvimento de todos os atores das instituições, viabilizando uma visão mais ampla da situação de saúde. Algumas etapas delineiam a análise situacional aplicada no momento explicativo do PES: caracterização da população no tocante aos aspectos sociodemográficos, comportamentais e epidemiológicos; identificação dos problemas; priorização; sistematização através de um fluxograma ou árvore de problemas; e apresentação dos resultados.

A escolha da população se deu desde o PIASC II, por ser um projeto da USF que estava em construção e os atores envolvidos objetivaram realizar intervenções que atendessem as demandas problematizadas pelo grupo. Nesta experiência, a população-alvo constituiu-se de parte dos usuários idosos participante do Projeto Saber Envelhecer, coordenado pela equipe de saúde da Unidade de Saúde da Família. Este projeto visa a promoção de saúde e qualidade de vida, através de rodas de conversa, palestras, dança, artesanato, entre outras estratégias para aprofundamento dos saberes relacionais. Para a realização do momento explicativo, a construção do instrumento de coleta foi articulada entre o corpo acadêmico e os profissionais de saúde da USF. Sendo assim, com a base teórica da estimativa rápida, dados não-estruturados e das necessidades em saúde, o instrumento de coleta foi construído levando-se em conta: dados sociodemográficos; dados clínicos implicados no processo de envelhecimento; estilo de vida; e avaliação das atividades do grupo de idosos sobre o Projeto Saber Envelhecer. Após a primeira avaliação docente, a proposta de instrumento foi socializada com os profissionais da USF, de modo que eles pudessem avaliar, discutir e contribuir sobre o que era pertinente ou não no questionário. Os estudantes, então, realizaram os ajustes do instrumento. As informações obtidas subsidiaram os momentos normativo, estratégico e tático-operacional.
Após a coleta, os dados foram dispostos no Microsoft ${ }^{\circledR}$ Excel ${ }^{\circledR}$ para análise estatística descritiva dos três primeiros blocos e análise de discursos do quarto bloco. Em seguida, foi construído um relatório analítico com contextualização teórica do envelhecimento populacional no Brasil; transição epidemiológica; a importância das políticas públicas de saúde do idoso; as ações de educação popular para este grupo; e descrição e discussão dos resultados do diagnóstico situacional. A análise foi apresentada à USF e discutida coletivamente de forma a subsidiar as intervenções desenvolvidas pelos estudantes no terceiro semestre do curso (PIASC III). Na análise dos discursos, foram destacadas as práticas exitosas realizadas nas oficinas e a sugestão de novas estratégias, ressaltando, inclusive, o desejo dos idosos de protagonizá-las, de forma a levar seus conhecimentos para outras pessoas da comunidade.

Com o objetivo de responder a essas demandas, o eixo temático do terceiro semestre do componente curricular constitui-se de três elementos para a formação do graduando em saúde no cerne da integração ensino-serviço-comunidade: Planejamento em Saúde, Educação Popular e Intervenção Comunitária (Quadro 1).

\section{Aprendendo a planejar em saúde na prática: do normativo ao tático-operacional}

A análise situacional foi retomada para priorização e sistematização dos problemas previamente identificados, nas quais os estudantes evidenciaram o que emergiu dos discursos, priorizando aqueles que apareceram com maior frequência, como forma de construir os momentos normativo, estratégico e táticooperacional do plano.

É importante ressaltar que o enfoque sobre a situação de saúde contou com o referencial teórico de Carlos Matus, conhecido como Planejamento Estratégico Situacional e composto por quatro momentos: explicativo (análise situacional), normativo (priorização dos problemas de modo a definir a chamada 'situação-objetivo'), estratégico (tomada de decisões do que será feito para alcançar a situação-objetivo, implicando análise de viabilidade) e tático-operacional (execução e avaliação das ações planejadas) ${ }^{9}$. Ao cumprir a etapa de identificação e discussão dos problemas com os profissionais de saúde, os estudantes realizaram o 
momento explicativo. Em seguida, ao priorizar as necessidades e estabelecer metas a serem alcançadas, de acordo com os discursos dos idosos e com a participação deles, desenhou-se o momento normativo. Foram planejadas 5 intervenções, as quais estiveram sob os moldes matusianos de planejamento, envolvendo construção de matriz de viabilidade e, posteriormente, matriz de avaliação (momentos estratégico e tático-operacional) (Quadro 2).

Quadro 2. Disposição das etapas operacionais do planejamento em saúde no Projeto Saber Envelhecer,

Programa de Integração Academia, Serviço e Comunidade, 2016-2017

\begin{tabular}{|c|c|}
\hline Momento* & Atividades \\
\hline $\begin{array}{l}\text { Explicativo } \\
\text { (conduzido } \\
\text { com a turma } \\
\text { cursando } \\
\text { PIASC II - } \\
\text { semestre } \\
2016.1^{1}\end{array}$ & $\begin{array}{l}\text { 1.Primeira reunião entre corpo acadêmico e equipe de saúde para levantamento e discussão do problema; } \\
\text { 2.Utilização de dados obtidos nos prontuários e oficinas anteriores; } \\
\text { 3.Construção prévia do instrumento de coleta; } \\
\text { 4.Segunda reunião entre corpo acadêmico e equipe de saúde para discussão do instrumento de coleta; } \\
\text { 5.Aplicação do instrumento pelos discentes com apoio dos ACSs; } \\
\text { 6. Compilação e análise dos dados; } \\
\text { 7.Apresentação dos dados à ESF. }\end{array}$ \\
\hline $\begin{array}{l}\text { Normativo } \\
\text { (conduzido } \\
\text { com a turma } \\
\text { cursando } \\
\text { PIASC III - } \\
\text { semestre } \\
\text { 2017.1) }\end{array}$ & $\begin{array}{l}\text { 1.Retomada dos discursos com destaque à reivindicação de protagonismo pelos idosos levando ao objetivo de } \\
\text { estabelecê-los como atores principais e planejadores das ações; } \\
\text { 2.Identificação, pelos idosos, do objetivo de realizar um passeio cultural por Salvador, pois muitos não haviam } \\
\text { tido a oportunidade de sair de sua comunidade; } \\
\text { 3.Reorientação do plano afim de atender ao novo desenho estratégico emergente das falas avaliativas dos atores } \\
\text { envolvidos: situação-objetivo; } \\
\text { 4. Definição do "deve ser", ou seja, das novas ações: a) organização das oficinas de forma que os idosos a } \\
\text { conduzissem, trazendo seus saberes já identificados no momento explicativo - protagonismo; b) demarcação da } \\
\text { data e do local para o passeio turístico objetivando a imersão cultural; c) permanência do espaço de diálogo para } \\
\text { que os integrantes do projeto mantivessem verbalizadas suas necessidades; } \\
\text { 5. Levantamento e quantificação dos recursos humanos, financeiros e estruturais das ações. }\end{array}$ \\
\hline $\begin{array}{l}\text { Estratégico } \\
\text { (conduzido } \\
\text { com a turma } \\
\text { cursando } \\
\text { PIASC III - } \\
\text { semestre } \\
2017.1 \text { ) }\end{array}$ & $\begin{array}{l}\text { 1.Construção das matrizes operativas, de viabilidade e avaliação para todas as ações a serem realizadas durante } \\
\text { o semestre; } \\
\text { 2. Definição do aporte organizacional e tecnológico necessários- análise de factibilidade; } \\
\text { 3. Levantamento dos custos e definição da forma de obtenção para que todas as ações fossem cobertas } \\
\text { financeiramente, mas sem ônus para os idosos - análise de factibilidade; } \\
\text { 4. Análise da coerência entre os objetivos e as ações desenhadas garantindo o protagonismo dos idosos e a } \\
\text { imersão cultural; } \\
\text { 3.Análise de viabilidade do apoio institucional: Universidade, Escola Estadual (local de realização das oficinas) e } \\
\text { Unidade de Saúde da Família, onde a Escola Estadual cedeu o espaço físico, a USF o suporte organizacional e a } \\
\text { UNEB, o logístico com o transporte urbano. }\end{array}$ \\
\hline $\begin{array}{l}\text { Tático- } \\
\text { operacional } \\
\text { (conduzido } \\
\text { com a turma } \\
\text { cursando } \\
\text { PIASC III - } \\
\text { semestre } \\
2017.1 \text { ) }\end{array}$ & $\begin{array}{l}\text { 1.As oficinas realizadas conseguiram o objetivo de trazer aos idosos o papel de protagonistas; } \\
\text { 2.O objetivo de passeio cultural por Salvador foi alcançado contando com a participação de todos os atores } \\
\text { envolvidos desde o planejamento das ações; } \\
\text { 3.Todas as etapas foram organizadas e avaliadas a cada execução para ajustes quando necessário, como } \\
\text { remanejamento de datas e supervisão para que os objetivos pudessem ser alcançados; } \\
\text { 4. Durante o monitoramento, os discentes apresentaram empatia e vínculo com os idosos, gerando afeto e maior } \\
\text { troca de saberes; } \\
\text { 5. A partir das experiências, emergiram relatos de permanência do protagonismo dos idosos e continuidade das } \\
\text { oficinas e retorno de alguns discentes para continuarem a participar nas ações, mesmo findado o componente } \\
\text { disciplinar, mas como extensionistas; } \\
\text { 6. Uma pequena evasão no final das atividades gerou a necessidade de aproximação dos participantes que se } \\
\text { afastaram, levando a uma nova análise situacional a ser avaliada e problematizada para enfrentamento e ajustes } \\
\text { entre o planejamento e a realidade. }\end{array}$ \\
\hline
\end{tabular}

Fonte: Elaboração própria tendo como embasamento teórico o Planejamento Estratégico em Saúde de Carlos Matus.

*Os autores compreendem a disposição didática dos momentos do PES e sua sobreposição operacional quando disposta na prática.

1 O quadro apresenta a sequência de 2016.1 - 2017.1 devido à decisão tomada pela Universidade do Estado da Bahia, de reprogramação do semestre de 2016.2 para 2017.1, a fim de regularizar o seu calendário após período de greve (http://www.uneb.br/files/2016/11/1223-Res-Regulamenta-a-Reprogramao-do-Sem.2016.2-para-2017.1.pdf). Assim, 2016.1 corresponde ao PIASC II e 2017.1 ao PIASC III por supressão regimental do semestre 2016.2. 
A primeira intervenção foi ambientada em um baile dos anos 1960, tendo sido este um pedido dos idosos na etapa de diagnóstico situacional. No baile, os estudantes realizaram uma dinâmica com as falas dos idosos obtidas no diagnóstico situacional. Foram selecionadas previamente de acordo com eixos: convivência no grupo e com a equipe da USF, relacionamento familiar; convívio social. As falas foram dispostas anonimamente em cartões em uma caixa, sorteadas aleatoriamente, lidas em voz alta e problematizadas pelos próprios idosos. As discussões levaram à maior compreensão das questões evidenciadas e a seleção de problemas, causas e consequências. Os participantes puderam externar suas sugestões de intervenções com ênfase em seu protagonismo, enquanto facilitadores das intervenções seguintes. Nesse sentido, o planejamento tomado como popular e participativo, buscou materializar a proposta de participação social como uma de suas diretrizes, envolvendo a comunidade, seus desejos, necessidades e problemas na construção do cuidado. A partir das sugestões dos idosos, e idealização de objetivos, foram planejadas mais quatro intervenções, sendo duas oficinas de artesanato; uma oficina de customização de camisetas e um passeio turístico a um ponto histórico da cidade.

A educação em saúde apresentou-se como uma ferramenta transformadora das práticas em saúde, intrínseca ao planejamento, ultrapassando a transmissão vertical de informação, com priorização das relações dialógicas entre a comunidade e o trabalhador de saúde e a (re)construção de conhecimentos através da articulação entre os saberes. Nessa perspectiva, esse paradigma da educação busca valorizar as experiências, de modo a instigar reflexões e produzir transformações no contexto do indivíduo e da comunidade, evidenciando suas potencialidades ${ }^{10}$.

As oficinas de artesanato foram conduzidas pelos próprios idosos, os quais puderam trazer seus conhecimentos, compartilhar com o grupo de discentes, docentes, equipe de saúde e outras pessoas da comunidade e (des)construí-los. Neste processo foram confeccionados tapetes, tiaras, presilhas, chaveiros com retalhos e fuxicos, customização de almofadas e panos de prato. Todos os participantes trouxeram suas contribuições, e as interações estabeleceram vínculos de cuidado e afetividade, responsabilização, diálogo e troca de conhecimentos intergeracionais com compartilhamento de suas histórias de vida.
A última intervenção de PIASC III, o passeio para o ponto turístico, contou com a participação de todos os atores: idosos, docentes, discentes e trabalhadores de saúde. À exceção do passeio, após cada intervenção houve o momento de avaliação como disparador de novas demandas para construção de novos planos; potencialização de ações para o grupo de idosos e reorganização de estratégias pedagógicas responsáveis pelo ativismo discente enquanto futuro trabalhador em saúde. Mallman e colaboradores ${ }^{11}$ afirmam a importância da reflexão das ações para empoderamento e construção coletiva do processo educativo e laborativo. Para os estudantes, a experiência no Planejamento Estratégico em Saúde visou a ressignificação das práticas de saúde como etapa inicial em processos de trabalho capazes de instrumentalizar o aporte teórico-prático do PES.

\section{Discutindo os achados, refletindo as práticas}

O envelhecimento populacional representa um processo de transição pelo qual diversos países, inclusive o Brasil, estão inseridos. As alterações nas taxas de mortalidade e de fecundidade que delineiam a transição demográfica proporcionaram um processo de inversão da pirâmide etária, com diminuição da população jovem e aumento da população idosa. No Brasil, este processo ocorreu concomitantemente à urbanização e a industrialização, de forma desordenada e em um curto período de tempo, o que inviabilizou o planejamento de infraestrutura adequada para atender às demandas emergentes desse contexto. A mudança para os centros urbanos gerou modificações nos hábitos de vida, ao mesmo tempo em que trouxe impactos no perfil de morbimortalidade da população, com aumento da carga de doença para as doenças crônicas não-transmissíveis - DCNT, configurando a transição epidemiológica ${ }^{11}$.

A análise situacional das condições de saúde e qualidade de vida dos idosos do Projeto Saber Envelhecer evidenciou problemas, demandas e necessidades de saúde referentes à autonomia/independência, capacidade funcional, inclusão social, lazer, o processo de envelhecimento ativo e suas consequências do ponto de vista individual e coletivo.

Veras e Oliveira ${ }^{12}$ apontam que as alterações morfofisiológicas e psicossociais advindas do envelhecimento resultam em limitações que acabam por interferir na vida da pessoa idosa, a qual passa a ter uma vida 
menos ativa, reclusa, acarretando em redução do convívio em sociedade e problemas emocionais. No que concerne à concepção dos idosos do que significa envelhecer bem, foi destacada a importância do convívio harmonioso com família e amigos; a ausência de preocupações ou aborrecimentos; o cuidado com a alimentação, o bem-estar psicológico e até mesmo a 'aceitação' do envelhecimento com manutenção da autonomia e protagonismo. Com os achados do momento explicativo, foram enfatizadas estratégias para construção de vínculo, como a 'dinâmica do abraço', na qual todos foram convidados a abraçar a pessoa mais próxima, expressando seu afeto.

Os idosos e profissionais de saúde expressaram a importância da parceria consolidada entre a Universidade e a USF na valorização do idoso como ser social e na qualificação do cuidado em saúde. Tal constatação é corroborada por Almeida et al. ${ }^{13}$, que traz a percepção de usuários de uma unidade de saúde no que se refere à inserção de graduandos de saúde no serviço, visto que a integração ensino-serviço viabiliza ao estudante vivenciar a realidade da atenção à saúde e adquirir experiência na prática através da imersão no contexto da comunidade, na qual o Planejamento Estratégico em Saúde instrumentaliza as ações em saúde.

As atividades educativas em grupo são fundamentais para a inserção social do idoso, possibilitando a criação de vínculos e uma rede de suporte recíproca, na qual os participantes podem compartilhar experiências, desenvolver uma análise crítica sobre sua forma de conduzir a vida e construir transformações de acordo com suas necessidades ${ }^{4,10}$.

Outrossim, Moraes e Costa ${ }^{14}$ ratificam a importância de um currículo diferenciado na formação profissional, visto que as práticas em saúde requerem uma composição multidisciplinar para efetivarem a interdisciplinaridade, uma potência presente no PIASC. O papel dos profissionais de saúde se insere na realidade do território em que vivem as comunidades para dar conta da resolubilidade, integralidade e pertinência dos problemas e necessidades de saúde. O desenvolvimento dessas competências reafirma que a formação ocorre em diferentes espaços, incluindo a educação permanente e processo de trabaIho em saúde, e deve ser uma realidade com diferencial na reestruturação transformadora das práticas, modelo de atenção, gestão do cuidado, controle social e planejamento em saúde.

\section{Conclusão}

A complexidade da organização do sistema de saúde no Brasil fez com que surgisse a demanda de profissionais aptos para atuar nos serviços. A integração ensino-serviço-comunidade proporcionada pelo componente curricular deste relato mostrou-se um instrumento potencializador de formação para o SUS, ao contribuir na inserção do discente nas práticas, em contato com a comunidade e a compreensão dos determinantes sociais no processo saúde-doença. As estratégias e as abordagens teóricas proporcionaram discernimento acerca do funcionamento do Sistema Único de Saúde, da organização da ESF como reestruturadora da atenção básica e a importância do aporte teórico da Saúde Coletiva para construção de suas práticas. Em adicional, a natureza do PIASC, ao comportar os discentes dos seis cursos de graduação da Universidade, proporcionou o trabalho em equipe e a prática interdisciplinar para a atenção.

No que tange ao cuidado em saúde, a experiência de Planejamento Estratégico em Saúde, em consonância com os princípios da Educação Popular, proporcionou um olhar crítico frente às necessidades de saúde apresentadas pelos idosos, visto que os estudantes puderam desenvolver a escuta qualificada, além de compreender e elaborar todo o percurso com base nos momentos do PES. A construção de vínculo, humanização, acolhimento e protagonismo dos usuários em todos os momentos perpassou na integração dos diversos saberes no embasamento de planos de ação.

\section{Contribuições dos autores}

Santos CML, participou da experiência, idealização do manuscrito, contribuiu com conteúdo intelectual crítico, escrita e aprovação versão final do manuscrito. Pinheiro-Ferreira SMS, participou da experiência, idealização do manuscrito, contribuiu com conteúdo intelectual crítico, escrita e aprovação versão final do manuscrito. Almeida CS, participou da experiência, idealização do manuscrito, contribuiu com conteúdo intelectual crítico, escrita e aprovação versão final do manuscrito. Araújo IB, participou da experiência, contribuiu com conteúdo intelectual crítico, escrita e aprovação versão final do manuscrito. Marino AC, participou da experiência, contribuiu com conteúdo intelectual crítico, escrita e aprovação versão final do manuscrito. Menezes VM, participou da experiência, contribuiu com conteúdo intelectual crítico, escrita e aprovação versão final do manuscrito. 


\section{Conflitos de interesses}

Nenhum conflito financeiro, legal ou político envolvendo terceiros (governo, empresas e fundações privadas, etc.) foi declarado para nenhum aspecto do trabalho submetido (incluindo mas não limitando-se a subvenções e financiamentos, conselho consultivo, desenho de estudo, preparação de manuscrito, análise estatística, etc.).

\section{Referências}

1. Junges JR, Barbiane R, Zoboli ELCP. Planejamento Estratégico como exigência ética para a equipe e a gestão local da Atenção Básica em Saúde. Interface. 2015;19(53):265-74. doi: 10.1590/1807-57622014.0331

2. Arantes LJ, Shimizu HE, Merchan-Hamann E. Contribuições e desafios da Estratégia Saúde da Família na atenção primária à saúde no Brasil: revisão da literatura. Ciênc. saúde coletiva. 2016;21(5):1499-510. doi: 10.1590/1413-81232015215.19602015

3. Costa DAS, Silva RF, Lima VV, Ribeiro ECO. Diretrizes curriculares nacionais das profissões da Saúde 2001-2004: análise à luz das teorias de desenvolvimento curricular. Interface. 2018;22(67):1183-95. doi: 10.1590/1807-57622017.0376

4. Moreira COF, Dias MSA. Diretrizes curriculares na saúde e as mudanças nos modelos de saúde e educação. ABCS Health Sci. 2015;40(3):300-5. doi: 10.7322/abcshs.v40i3.811

5. Borde E, Hernández-Álvarez M, Porto MFS. Uma análise crítica da abordagem dos determinantes sociais da saúde a partir da medicina social e saúde coletiva latino-americana. Saúde Debate. 2015;39(106):841-54. doi: 10.1590/0103-1104201510600030023

6. Fertonani HP, Pires DEP, Biff D, Scherer MDA. Modelo assistencial em saúde: conceitos e desafios para a atenção básica brasileira. Ciênc. saúde coletiva. 2015;20(6):1869-878. doi: 10.1590/1413-81232015206.13272014

7. Kleba ME, Duarte TF, Romanini A, Cigognini DC, Althaus IR. Estimativa rápida participativa como ferramenta de diagnóstico na Estratégia de Saúde da Família. Revista Grifos. 2015;24(3839):159-77. doi: $10.22295 /$ grifos.v24i38/39.3279

8. Teixeira CF, Vilasbôas ALQ, Jesus WLA. Proposta metodológica para o planejamento no Sistema Único de Saúde. In: Teixeira C. Planejamento em Saúde: Conceitos, Métodos e Experiências. Salvador; Edufba; 2010.

9. Matus C. Adeus, senhor presidente: governantes governados. São Paulo: Edições Fundap; 1996.

10. Mallmann DG, Galindo Neto NM, Sousa JC, Vasconcelos EMR. Educação em saúde como principal alternativa para promover a saúde do idoso. Ciênc. saúde coletiva. 2015;20(6):1763-772. doi: 10.1590/1413-81232015206.02382014
11. Miranda GMD, Mendes ACG, Silva ALA. O envelhecimento populacional brasileiro: desafios e consequências sociais atuais e futuras. Rev. Bras. Geriatr. Gerontol. 2016;19(3):507-19. doi: $\underline{10.1590 / 1809-98232016019.150140}$

12. Veras RP, Oliveira M. Envelhecer no Brasil: a construção de um modelo de cuidado. Ciênc. saúde coletiva. 2018;23(6):1929-936. doi: $10.1590 / 1413-81232018236.04722018$

13. Almeida FCM, Maciel APP, Bastos AR, Barros FC, Ibiapina $J R$, Souza SMF et al. Avaliação da inserção do estudante na unidade básica de saúde: visão do usuário. Rev. bras. educ. med. 2012;36(1 supl. 1):33-9. doi: 10.1590/S0100-55022012000200005

14. Moraes BA, Costa NMSC. Compreendendo os currículos à luz dos norteadores da formação em saúde no Brasil. Rev Esc Enferm USP. 2016;50:9-16. doi: 10.1590/S0080$\underline{623420160000300002}$ 